\title{
Transference Number Measurement of Zinc Salts in Aqueous Solution
}

\author{
Ahlam M. Farhan* Ghadah A.Yiseen** Zahraa A.Mahmood*
}

\begin{abstract}
Date of acceptance $1 / 3 / 2010$

Transference numbers of the aqueous zinc chloride and zinc sulphate solutions have been measured for the concentrations $0.03,0.05,0.07,0.09$ and $0.1 \mathrm{~mol} . \mathrm{dm}^{-3}$ at $298.15 \mathrm{~K}$, by using the modified Hittorf method. The dependence of transference number on concentration of each electrolyte was also investigated in an attempt to explain the value of the limiting transference number. The Longsworth method has been used for the extrapolation of zinc transference number in aqueous solutions, using the values of the limiting transference numbers of the appropriate values of the limiting equivalent conductance, it was possible to determine the corresponding values of the limiting ion conductance for the cations and anions of the electrolytes. The density and specific conductivity of all solutions have been measured at $298.15 \mathrm{~K}$
\end{abstract}

\section{Key words: Transference Number, Zinc Salts, Measurement.}

\section{Introduction}

The current passed through an electrolyte solution is carried by solvated ion, positive cations towards the negative cathode, and negative anions moving towards the positive anode. However, mobilities, and hence conductivities, of the cations and anions in an electrolyte solution are different. Consequently, different fractions of the total current are carried by the different ions. These fractions are known as the transference numbers of the cations and anions $[1,2]$ is expressed by:

$\tau_{\mathrm{i}}=\mathrm{i}_{\mathrm{i}} / \Sigma_{\mathrm{j}} \mathrm{i}_{\mathrm{j}}=\mathrm{c}_{\mathrm{i}} \mathrm{z}_{\mathrm{i}} \mathrm{u}_{\mathrm{i}} / \Sigma_{\mathrm{j}} \mathrm{c}_{\mathrm{j}} \mathrm{z}_{\mathrm{j}} \mathrm{u}_{\mathrm{j}}$

(1)

Where :

$\tau_{\mathrm{i}}=$ transference number of ion $\mathrm{i}, \mathrm{i}_{\mathrm{i}}=$ current carried by the ion $\mathrm{i}, \Sigma_{\mathrm{j}} \mathrm{i}_{\mathrm{j}}=$ current carried by all the ions in the solution, $c_{i}=$ concentration of ion $i$, $\mathrm{z}_{\mathrm{i}}=$ charge of the ion $\mathrm{i}, \mathrm{u}_{\mathrm{i}}=$ mobility of the ion $\mathrm{i}$.
The sum of the transference numbers, of all kinds of ions present in a solutions is: $\sum \tau_{\mathrm{i}}=1$

The transference number of every ion depends on the concentration of ions in solution, the charge, and mobility of ion, the temperature and potential gradient. The variation of transference numbers with concentration is a consequence of the interionic attraction, the degree hydration, and the degree of ion association and the tendency of ions to form ionic complex [3].

Studies were initialed on aqueous solution of zinc perchloride to allow comparisons between complexed and uncomplexed of zinc salts [4]. It is certain that complexing of the type observed for the halide salts, is not possible in zinc perchlorate. Raman studies on zinc hailed[5], which have provided independent evidence of complexion have give negative results

\footnotetext{
*University of Baghdad / College of Science for Women/ Dep.of Chemistry

**University of Baghdad /College of Science /Dep.of Chemistry
} 
for both zinc nitrate and zinc perchlorate[6]. The activity coefficients for both salts and transference number for zinc perchlorate[4] show a normal behavior and certainly no evidence for complexation. There is, however, some doubt about the possibility of ion-pair formation. Using conductance measurements, Davies and Karl[4] found no evidence for ion association, although Dye, Faber and $\operatorname{Karl}[8]$ considered the conductance anomalous. They were unable to assign any effect due to the presence of the ion-pair $\mathrm{ZnclO}_{4}^{+}$. Znic chloride is much less complexed [9] salt, and there is no possibility to predict its transport properties by such theories. It is therefore instructive to compare its transport properties with those of zinc perclorate, which is completely dissociative at concentrations up to 3.0 mol. dm ${ }^{-3}$.

The aim of this work is to measure the transference numbers of some zinc ions by using Hittorf method at $298.15 \mathrm{~K}$.

\section{Materials and Methods}

The zinc chloride and zinc sulphate are used from (Riede-De Haen AG, Seelze-Hhnnover Company) in more than (99.5\%). Copper sulphate (General Purpose Reagent, Hopkin and Williams). The solution of $0.1 \mathrm{M}$ are prepared from zinc chloride and zinc sulphate. In addition to this, we have prepared solutions of different concentrations of $\mathrm{ZnCl}_{2}$ and $\mathrm{ZnSO}_{4}$ within range of $(0.03,0.05,0.07$ and 0.09) M

The Hittorf cell of $225 \mathrm{~cm}^{3}$ capacity used in this work were initially design by Macinnes and Dole[10], along with there compartments, the cathode and anode compartments of the cell contained a $99.9 \%$ pure zinc rod electrode. The current was obtained from potential differences, measured across standard resistors which were placed at each end of the cell, in order to detect any current leakages. The cell compartments were in a thermostat bath, which was maintained at $298.15 \mathrm{~K}$. A direct current of $9.1 \mathrm{~mA}$ (measured accurately with a digital current meter as well as by a copper coulometer), was passed through the solution with the help of a current stabilizer for 3 hour, to bring about a measurable change in zinc chloride and zinc sulphate concentrations in the electrode compartments. The density of all solutions as well as that for the anode and cathode solutions after experiment were measured accurately using the pecnometer at $298.15 \mathrm{~K}$

The conductance of all solutions was measured at $298.15 \mathrm{~K}$ with the aid of a conductivity meter model (CAN/CSA STD c22. No.61010-1 made in Germany), a digital conductivity meter.

\section{Results and Discussion \\ Transference number :}

Transference number was determined by the Hittorf method. From the definition of transference number, $\tau_{+}{ }^{\mathrm{h}} \mathrm{i} \Theta / 2 \mathrm{~F} 10^{3}$ moles of zinc are transported by a current of $\mathrm{i} / \mathrm{mA}$, during a time, $\Theta / \mathrm{s}$. Allowing for electrode reactions at the zinc rod electrodes, the change in the number of moles of zinc, $\Delta \mathrm{n}$, in anodic and cathodic compartments can be calculated[2]:

$\Delta \mathrm{n}_{\text {anode }}=\left(1-\tau_{+}{ }^{\mathrm{h}}\right) \mathrm{i} \Theta / 2 \mathrm{~F} 10^{3}$ (3)

$\Delta \mathrm{n}_{\text {cathode }}=\left(\tau_{+}{ }^{\mathrm{h}}-1\right) \mathrm{i} \Theta / 2 \mathrm{~F} 10^{3}$ (4)

The change in number of moles $\mathrm{Cu}^{+2}$ ion in each compartment (anodic and cathodic compartments) are calculated according to the following equation: $\Delta \mathrm{n}=\mathrm{W}\left(\mathrm{m}_{\mathrm{f}}-\mathrm{m}_{\mathrm{i}}\right) / 10^{3}-\mathrm{m}_{\mathrm{i}} \mathrm{M}_{\mathrm{s}}(5)$ 
Where $\mathrm{M}_{\mathrm{s}}$ is the molecular weight of the salt. $\mathrm{m}_{\mathrm{f}}$ and $\mathrm{m}_{\mathrm{i}}$ are the molal From eqn.(3)- eqn.(5) we get: concentration of ion befor and after the experiment.

$$
\left(1-\tau_{+}{ }^{\mathrm{h}}\right)=\tau^{\mathrm{h}} \equiv \frac{2 \mathrm{~F}}{\mathrm{i}} \frac{\mathrm{W}}{1-\mathrm{m}_{\mathrm{i}} \mathrm{Ms} 10^{-3}} \quad\left(\mathrm{~m}_{\mathrm{f}}-\mathrm{m}_{\mathrm{i}}\right)
$$

Experimental results are summarized in Table (1) of the zinc chloride and Table (2) for zinc sulphate. Table (1 and 2):- The transference number of ions $\tau_{\mathrm{i}}$ for $\mathrm{ZnCl}_{2}$ and $\mathrm{ZnSO}_{4}$ electrolyte which are used in Hittorf method in which $(\mathrm{C}, \mathrm{m}, \mathrm{W}$ and $\rho)$, respectively, are the molar and molal concentrations, the weight and density of solutions. The symbols (i, a and c) refers to the initial, anodic and cathodic compartment solutions, respectively at temperature $298.15 \mathrm{~K}$

Table (1) for $\mathrm{ZnCl}_{2}$

(A)

\begin{tabular}{|c|c|c|c|c|c|c|}
\hline$C_{i} \backslash \mathbf{m o l} . d^{-3}$ & $W_{i} \mid g m$ & $\rho_{\mathrm{i}} \backslash \operatorname{lgm}_{3} . \mathrm{cm}^{-}$ & $\mathrm{m}_{\mathrm{i}} \mid \mathbf{m o l} \mathrm{kg}^{-1}$ & $\mathrm{C}_{\mathrm{a}} \mid \mathrm{mol} \mathrm{dm}^{-3}$ & $W_{\mathrm{a}} \mid \mathrm{gm}$ & $\rho_{\mathrm{a}} \mid \mathbf{g m} . \mathrm{cm}^{-3}$ \\
\hline 0.03 & 4.9446 & 0.98892 & 0.030462172 & 0.036 & 4.9559 & 0.99118 \\
\hline 0.05 & 4.9551 & 0.99102 & 0.050802682 & 0.067 & 4.9661 & 0.99322 \\
\hline 0.07 & 4.9747 & 0.99494 & 0.071037719 & 0.088 & 4.9767 & 0.99534 \\
\hline 0.09 & 4.9945 & 0.99890 & 0.091220160 & 0.140 & 4.9987 & 0.99974 \\
\hline 0.1 & 4.9955 & 0.99910 & 0.101475453 & 0.170 & 4.9930 & 0.99986 \\
\hline
\end{tabular}

(B)

\begin{tabular}{|c|c|c|c|c|c|c|}
\hline $\mathbf{m}_{\mathbf{a}} \backslash \mathbf{m o l} . \mathbf{K g}^{-\mathbf{1}}$ & $\mathbf{C}_{\mathbf{c}} \backslash \mathbf{m o l . d m}$ & $\mathbf{W}_{\mathbf{c}} \backslash \mathbf{g m}$ & $\rho_{\mathbf{c}} \backslash \mathbf{g m . \mathbf { c m } ^ { - 3 }}$ & $\mathbf{m}_{\mathbf{c}} \backslash \mathbf{m o l} . \mathbf{K g}^{-1}$ & $\tau_{\mathbf{z n}}{ }^{2+}$ & $\tau_{\mathbf{C l}}{ }^{-}$ \\
\hline 0.036501175 & 0.028 & 4.9416 & 0.98832 & 0.028330904 & 0.940981494 & 0.059018506 \\
\hline 0.068088381 & 0.045 & 4.9524 & 0.99048 & 0.045715818 & 0.830248161 & 0.169751838 \\
\hline 0.089491204 & 0.063 & 4.9704 & 0.99408 & 0.063927796 & 0.817887075 & 0.182112924 \\
\hline 0.142763327 & 0.086 & 4.9922 & 0.99844 & 0.087158369 & 0.487660385 & 0.512339614 \\
\hline 0.174060482 & 0.095 & 4.9898 & 0.99796 & 0.096446504 & 0.277482147 & 0.722517852 \\
\hline
\end{tabular}

(A)

Table (2) for $\mathrm{ZnSO}_{4}$

\begin{tabular}{|c|c|c|c|c|c|c|}
\hline $\mathbf{C}_{\mathbf{i}} \backslash \mathbf{m o l . d m}$ & $\mathbf{W}_{\mathbf{i}} \backslash \mathbf{g m}$ & $\rho_{\mathbf{i}} \backslash \mathbf{g m . \mathbf { c m } ^ { - 3 }}$ & $\mathbf{m}_{\mathbf{i}} \mid \mathbf{m o l . k \mathbf { k g } ^ { - 1 }}$ & $\mathbf{C}_{\mathbf{a}} \mid \mathbf{m o l . d m ^ { - 3 }}$ & $\mathbf{W}_{\mathbf{a}} \backslash \mathbf{g m}$ & $\rho_{\mathbf{a}} \backslash \mathbf{g m . \mathbf { c m } ^ { - 3 }}$ \\
\hline 0.03 & 4.9587 & 0.99174 & 0.030515287 & 0.038 & 4.9682 & 0.99364 \\
\hline 0.05 & 4.9740 & 0.99480 & 0.050998395 & 0.054 & 4.9817 & 0.99634 \\
\hline 0.07 & 4.9849 & 0.99698 & 0.071658742 & 0.079 & 4.9898 & 0.99796 \\
\hline 0.09 & 4.9982 & 0.99964 & 0.092425105 & 0.0995 & 5.0171 & 1.00342 \\
\hline 0.1 & 5.0133 & 1.00266 & 0.102679314 & 0.140 & 5.0256 & 1.00512 \\
\hline
\end{tabular}

(B)

\begin{tabular}{|c|c|c|c|c|c|c|}
\hline $\mathrm{m}_{\mathrm{a}} \mid \mathrm{mol} \mathrm{Kg}^{-1}$ & $\mathrm{C}_{\mathrm{c}} \backslash \mathrm{mol} \mathrm{dm}^{-3}$ & $W_{c} \backslash g m$ & $\rho_{\mathrm{c}} \mid \mathrm{gm} . \mathrm{cm}^{-3}$ & $\mathrm{~m}_{\mathrm{c}} \mid \mathrm{mol} . \mathrm{Kg}^{-1}$ & $\tau_{\mathrm{zn}}{ }^{2+}$ & $\tau_{\mathrm{SO} 4}=$ \\
\hline 0.038668442 & 0024 & 4.9526 & 0.99052 & 0.024399690 & 0.960211978 & 0.039788020 \\
\hline 0.0 & & 29 & & & 0.959710180 & 0289819 \\
\hline 0.081 & & 4.9822 & & 5268 & 0.906487240 & 3512759 \\
\hline 0.102071196 & 85 & 4.9931 & 0.99862 & 252949 & 0.902367541 & 0.097632458 \\
\hline 0.145098109 & 0.098 & 5.0097 & 1.00194 & 0.100640703 & 0.568626173 & 0.431373826 \\
\hline
\end{tabular}




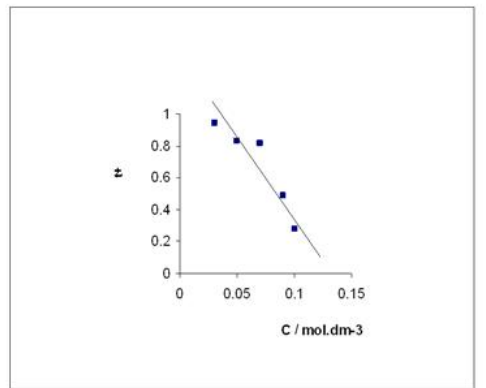

Fig. (1)-zinc transference number $\left(\tau_{+}\right)$as afunction of the molal concentration for aqueous zinc chloride at $298.15 \mathrm{~K}$.

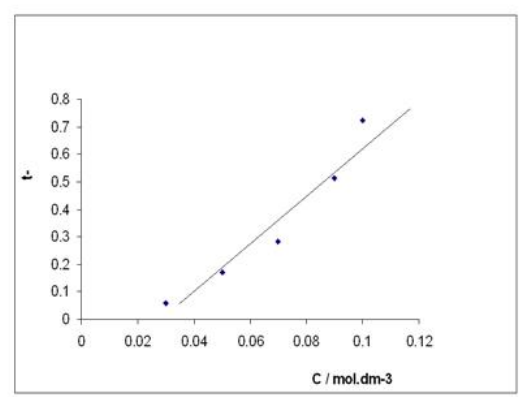

Fig. (2)-chloride transference number $\left(\tau_{-}\right)$as afunction of the molal concentration for aqueous zinc chloride at $298.15 \mathrm{~K}$.

The results of the transference number values calculated for all ions are drawn in figures 1 and 2. M. Spin ${ }^{(11)}$ show that the transference number of $\mathrm{Zn}$ ions will decrease with increasing the ion concentration. These results are in agreement with the relation $\left(\partial \tau_{\mathrm{i}} / \partial \mathrm{c}\right)_{\mathrm{T}}$ $<0$. From the figures of this study, we notice that the transference number for the $\mathrm{Cl}^{-}$and $\mathrm{SO}_{4}{ }^{2-}$ ions, fig. 2 , and fig. 4 show a different behavior, i.e., the transference numbers of these ions increase with increasing ion concentration. These results are in agreement with the relation $\left(\partial \tau_{\mathrm{i}} / \partial \mathrm{c}\right.$ ) $\mathrm{T}^{>} 0$. Also, we found that the transference number values of the $\mathrm{Zn}$ ions were a little higher than that listed by Angew and Paterson ${ }^{(4),(9)}$. This difference might be due to the high concentration which is within $0.1-0.3$ $\mathrm{mol} / \mathrm{dm}$. Maquillan ${ }^{(10)}$ pointed out that the increase in transference number of the $\mathrm{Zn}$ ion in $\mathrm{ZnCl}_{2}$ due to the formation of $\mathrm{ZnCl}_{4}{ }^{2-}$ complexes in the concentrated solution. Nothing was found in the literatures that match a similar behavior for zinc sulphate solution shown in figures $3 \& 4$.

The decrease in ions transference number of the transference elements with increasing concentration, fig.1, might be due to an increase in solution viscosity, which in turn cause an obstruction in ionic movement that results in a decrease in the carried electric current breakage by that ions. This process will lead to a decrease in transference number of the ions. On the other hand, the increase in the element ions concentration in solution results in an increase in a mutual effect among these ions, which is well known in electrolyte conductivity method to obstruct conductivity movement of these ions, and results in a decrease in transference number. 


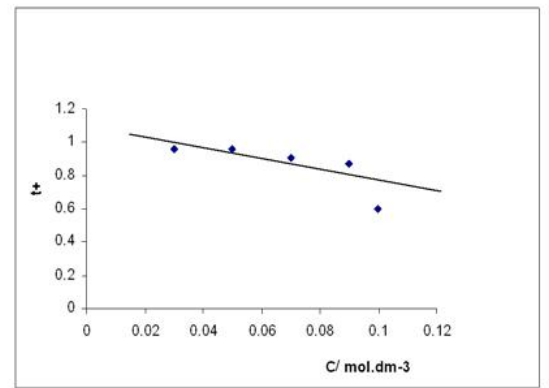

Fig. (3) Zinc transference number $\left(\tau_{+}\right)$as a function of the zinc sulphate concentration at $298.15 \mathrm{~K}$.

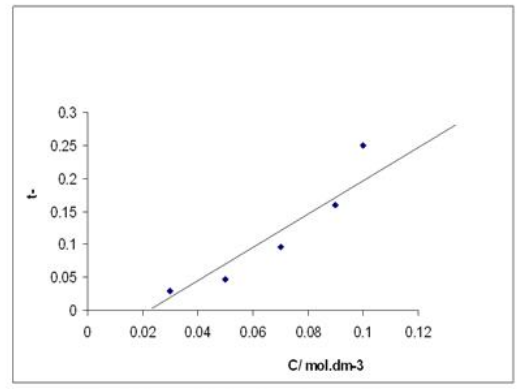

Fig (4)-sulphate transference number $\left(\tau_{-}\right)$as a function of the molal concentration for aqueous zinc sulphate at $289.15 \mathrm{~K}$.

\section{Limiting transference number:}

The limiting transference number of an ion, like the equivalent conductance value of an electrolyte, can not be measured directly. It can be extrapolated from the transference number data at different concentrations of an electrolyte. The Longsworth function $^{(12)}$ has been used for the extrapolation of transference number of cations to infinite dilution in order to obtain the limiting cation transference number values in all cases. The Longsworth function in each case was calculated by the method reported by Kay and Dye (12) by using the following equations:

$$
\bar{\tau}_{i}^{\circ}=\tau_{i}+\left(0.5-\tau_{i}\right)^{\Lambda \mathrm{e}}
$$

Where:

$$
\begin{aligned}
& \mathrm{B} \sqrt{ } \mathrm{C} \\
& \Lambda_{\mathrm{e}}=\frac{\mathrm{B} / \mathrm{C}}{1+\mathrm{Ka}^{\circ}} \\
& \text { And } \\
& 82.487 \\
& \mathrm{~B}=\frac{}{\eta(\mathrm{DT})^{1 / 2}}(9) \\
& 50.2916 \sqrt{ } \mathrm{C} \\
& \mathrm{K}=\frac{(10)}{(\mathrm{DT})^{1 / 2}} \\
& \mathrm{a}^{\circ}=\frac{Z_{+} Z_{-} \mathrm{e}^{2}}{2 \mathrm{DKT}}
\end{aligned}
$$

Thus, the Longsworth function values are calculated and reported in Tables (3) and (4), not the compatibility between the values of the number of cations $\left(\tau_{+}^{\mathrm{h}}\right)$ calculate in a direct and extrapolation between the values of a function to longsworth $\left(\tau^{\circ}{ }_{i}\right)$ of these ions and at the same concentrations.

Table (3)-Cation transference number and the corresponding Longsworth function as a function of normal concentration for zinc chloride at $298.15 \mathrm{~K}$.

\begin{tabular}{|c|c|c|}
\hline Cleq..dm & ${ }_{3} \tau^{\mathbf{h}}$ & $\boldsymbol{\tau}_{\mathbf{i}}$ \\
\hline 0.06 & 0.940981494 & 0.940437504 \\
\hline 0.10 & 0.830248161 & 0.829637591 \\
\hline 0.14 & 0.817887075 & 0.817124867 \\
\hline 0.18 & 0.487660385 & 0.487696127 \\
\hline 0.20 & 0.277482147 & 0.277697796 \\
\hline
\end{tabular}

Table (4)-Cation transference number and the corresponding Longsworth function as a function of normal concentration for zinc sulphate at $298.15 \mathrm{~K}$.

\begin{tabular}{|c|c|c|}
\hline Cleq.dm $^{-3}$ & $\boldsymbol{\tau}^{\mathbf{h}}$ & $\overline{\boldsymbol{\tau}_{\mathbf{i}}}$ \\
\hline 0.06 & 0.96021197 & 0.95914374 \\
\hline 0.10 & 0.95971018 & 0.95817726 \\
\hline 0.14 & 0.90648724 & 0.90473727 \\
\hline 0.18 & 0.90236754 & 0.90009464 \\
\hline 0.20 & 0.56862617 & 0.56855029 \\
\hline
\end{tabular}


Specific conductivity and equivalent conductance:

The specific conductivity (L) of all solutions has been measured at $298.15 \mathrm{~K}$ The corresponding values of equivalent conductance $(\Lambda)$ have been calculated. The change in the specific conductivity with the concentration of zinc chloride and zinc sulphate, and the calculated equivalent conductance against the square root of the concentration are presented in Tables (5) and (6) and shown in figs.(5) and (6).

Table (5)- The variation of specific conductivity (L) and equivalent conductance $(\Lambda)$ of the zinc chloride at $298.15 \mathrm{~K}$ with concentration.

\begin{tabular}{|c|c|c|c|c|c|c|c|c|}
\hline $\begin{array}{c}\text { Lil } \\
\text { ms.cm }\end{array}$ & $\begin{array}{l}C_{i} \mid \\
l \cdot m^{-3}\end{array}$ & $\begin{array}{c}\Delta \text { iil } \\
\mathrm{m}^{2} \text {.S.eq }\end{array}$ & $\begin{array}{l}\text { Lal } \\
\text { S.cm } \\
\text { S.cm }\end{array}$ & $\begin{array}{c}C_{a l} \\
\text { eq.dm }\end{array}$ & $\begin{array}{c}\Lambda_{\mathrm{a}} \mathrm{l} \\
\mathrm{cm}^{2} \cdot \mathrm{S}^{-} \cdot \mathrm{eq}^{-1}\end{array}$ & $\begin{array}{c}\mathrm{Lcl} \\
\mathrm{mS} . \mathrm{cm}^{-1}\end{array}$ & $\begin{array}{l}C_{c} l \\
q . d m^{-3}\end{array}$ & $\begin{array}{c}\Lambda_{\mathrm{c}} \mathbf{} \\
\mathrm{cm}^{2} \text {.S.eq }\end{array}$ \\
\hline 6.8 & & & & & & & & \\
\hline 9.87 & & & & & & & & \\
\hline & & & & & & & & \\
\hline 15. & & & & & 79 & & & 92.26 \\
\hline 7.70 & 0 & 0.50 & 25.17 & 0.340 & 74.02 & 16.95 & 0.190 & 89.21 \\
\hline
\end{tabular}

Table (6)- The variation of specific conductivity (L) and equivalent conductance $(\Lambda)$ of the zinc sulphate at $298.15 \mathrm{~K}$ with concentration.

\begin{tabular}{|c|c|c|c|c|c|c|c|c|}
\hline $\begin{array}{c}\text { Lil } \\
\text { ms.cm }^{-1}\end{array}$ & $\begin{array}{c}C_{i} \mid \\
\text { eq. } \text { dm }^{-3}\end{array}$ & $\begin{array}{c}\Delta \mathrm{il} \\
\mathrm{cm}^{2} . \mathrm{S} \cdot \mathrm{eq}^{-1}\end{array}$ & $\begin{array}{c}\text { Lal } \\
\mathrm{mS} . \mathrm{cm}^{-1}\end{array}$ & 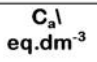 & $\begin{array}{c}\Lambda_{\mathrm{a}} \mathbf{l} \\
\mathrm{cm}^{2} \cdot \mathrm{S}^{-1} \mathrm{q}^{-1}\end{array}$ & $\begin{array}{c}\mathrm{Lcl} \\
\mathrm{mS} . \mathrm{cm}^{-1}\end{array}$ & $\begin{array}{c}\mathrm{C}_{\mathrm{c}} \mathrm{I} \\
\text { eq. } \mathrm{dm}^{-3}\end{array}$ & $\begin{array}{c}\Lambda_{\mathrm{c}} \mathrm{l} \\
\mathrm{cm}^{2} \text {.S.eq }\end{array}$ \\
\hline 3.84 & 0.06 & 64.00 & 4.31 & 0.068 & 63.38 & 3.80 & 0.048 & 79.16 \\
\hline 5.75 & 0.10 & 57.50 & 5.78 & 0.108 & 53.51 & 5.71 & 0.088 & 64.88 \\
\hline 7.38 & 0.14 & 52.71 & 7.78 & 0.158 & 49.24 & 7.31 & 0.136 & 53.75 \\
\hline 8.92 & 0.18 & 49.55 & 8.93 & 0.199 & 44.87 & 8.91 & 0.170 & 52.41 \\
\hline 9.55 & 0.20 & 47.75 & 9.68 & 0.280 & 34.57 & 9.56 & 0.196 & 48.77 \\
\hline
\end{tabular}

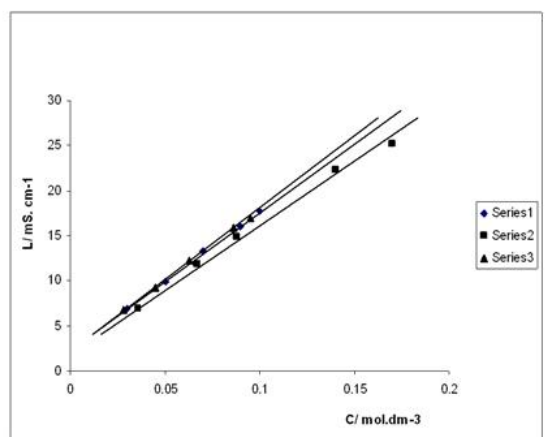

Fig. (5)-the variation of electrical conductivity of zinc chloride with concentration at $298.15 \mathrm{~K}$; series 1 of the initial, series 2 of the anodic and series 3 of the cathodic.

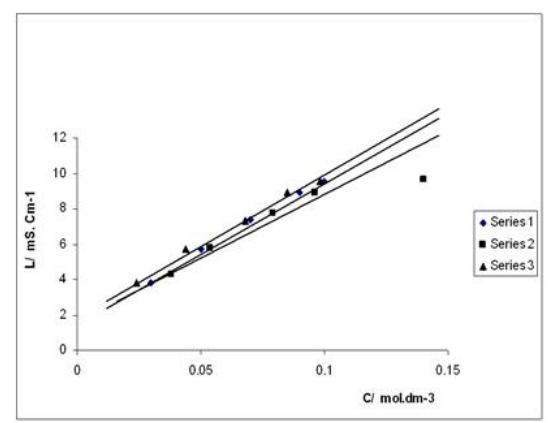

Fig (6)-the variation of electrical conductivity of zinc sulphate with concentration at $298.15 \mathrm{~K}$; series 1 of the initial, series 2 of the anodic and series 3 of the cathodic. 


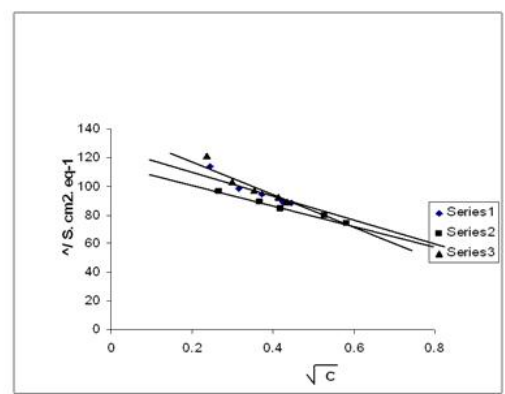

Fig. (7)-the variation of equivalent conductance of zinc chloride with sequre

root of concentration at $298.15 \mathrm{~K}$; series 1 of the initial, series 2 of the anodic and series 3 of the cathodic.

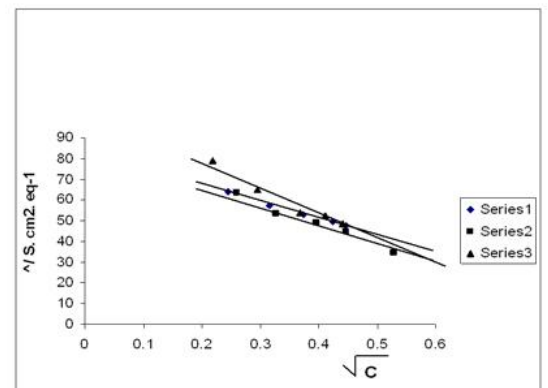

fig.(8)-the variation of equivalent conductance of zinc sulphate with sequre root of concentration at 298.15K; series 1 of the initial, series 2 of the anodic and series 3 of the cathodic.

A previous work $[14,16]$ on the relation between the electrical conductivity and the concentration of dispersed particles show that the conductivity increases with increasing the dispersed particle concentration. In the present work, we, clearly, got a similar relation as shown in fig .5. for zinc chloride and fig.6. for zinc sulphate. In the zinc chloride case, the increase in electrical conductivity might be due to the presence of three species: $\mathrm{Cl}_{3}^{-}, \mathrm{HClO}$ and dissolved chlorine[17]. Also, the electrical conductivity will increase by increasing the concentration because of increasing of the number of ions, which present in the solution.

The values of equivalent conductance $(\Lambda)$ for all solution are decrease with the increasing of electrolyte concentration in solution, which is refer in Table $(5,6)$ and figs. $(7,8)$. This is related to the ability of forming a groupings and ionic - pairs, which in turn obstruct the ions movement and preclude its influential charges as it explained theoretically in Deby - Hukel theory and electrolytic of conductivity theory $[18,19]$.

\section{References}

1. P. W. Atkins, "Physical chemistry", Oxford Press (1982)

2. Compton and Sanders "Electrode Potentials", Butter Worths, London, (1964).

3. A. L. Horvath, "Hand Book of Aqueous Electrolyte Solution", Ellis Horwood Ltd. (1985)

4. A. Angew and R. Paterson, J. Chem. Soc., Faraday Trans. I, 74, 2885 (1978).

5. D. E. Irish, B. McCarrol and T. F. Young, J. Chem. Phys.,39, 3436 (1963)

6. D. E. Irish, A. R. Davies and R. A. Plane, J. Chem. Phys., 50, 2262, (1969).

7. J. L. Dye, M. P. Faber and D. J. Karl, J. Amer. Chem. Soc., 82, 314 (1960)

8. V. Frei and J. Podlahave, Chem. Z., 67, 47 (1963).

9. A. Agnew and R. Paterson, J. Chem. Soc., Faraday Trans. I, 74, 2896 (1978).

10. A. J. Maquillan, J. Chem. Soc., Faraday Trans. I, 70, 1558 (1974).

11. M. Spin, "In Techniques of Chemistry", ed. A. Weissberger and W. P. Rossiter, New York, Vol. 1 (1971).

12. Dewey, This Journal, 47, 1927 (1925) 
13. M. Ottoy, T. Forland, S. K. Rakkje and S. M. Holst, J. Momb. Scie., 74, 1-8 (1992).

14. S. P. Anantha, "Transport Studies of Some Sodium ion Conducting Dispersed Solid Electrolytes. Polymer Electrolytes and Glasses, A Thesis", Department of Physics, Indian Institute of Technology Madras (2004)

15. V. Thangadurai and W.Weppner, Chem., Mater., 14, 1136 (2002).
16. N. A. Fried, K.G. Rhoads and D. R. Sadoway, Electrochem. Acta, 46, 3351 (2001).

17. B. K. Thomas and D. J. Fray, J. Applied Electrochem., 12, 1-5 (1982).

18. T. Eedey - Gruz, "Transport Phenomena in Aqueous Solutions",Academia Kiado, Budopest) (1974).

19. J. M. Salah, "Electrochemistry", $2^{\text {th }}$ , Baghdad, Press Iraq (1992).

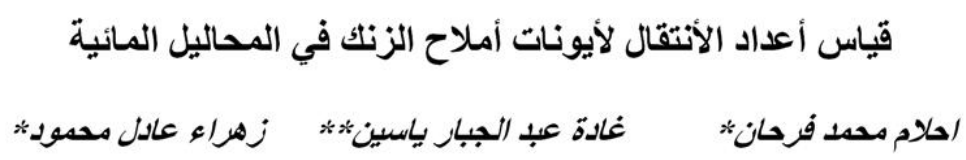

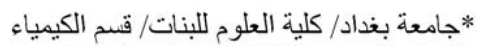

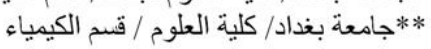

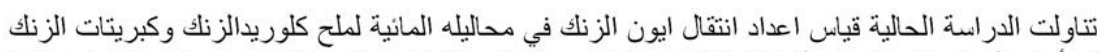

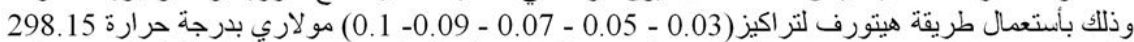

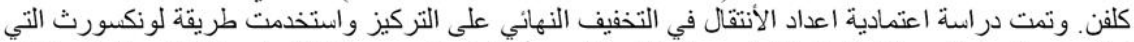

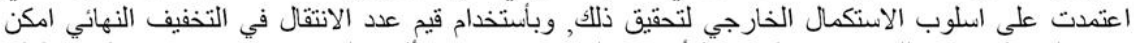

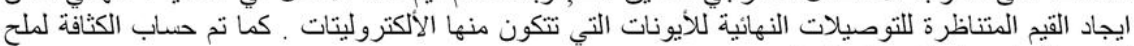

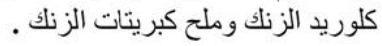

